\title{
MANIFESTAÇÕES NEUROLÓGICAS DA MALÁRIA
}

\author{
Fernando Guilhon Henriques *
}

Sob a denominação de malária nervosa agrupam-se as formas clínicas do impaludismo em que se evidencia o acometimento do sistema nervoso central. Na quase totalidade dos casos o agente causal é o Plasmodium falciparum, havendo poucos casos registrados na literatura médica determinados pelo Plasmodium vivax ${ }^{11}$. Daroff e col. ${ }^{7}$, em trabalho realizado no Vietnã, observaram, em 1200 casos de malária causada por $P$. falciparum, a incidência de $1,6 \%$ de formas com sintomatologia neurológica. Parece haver maior número de casos nas crianças e adolescentes, pois nos indivíduos adultos, habitantes de zonas endêmicas, pode desenvolver-se imunidade ao impaludismo, comprovada pelo encontro de anticorpos antimalária no sangue 16, 21. Nas crianças de poucos meses parece haver certa proteção por anticorpos originados da mãe durante a gestação ${ }^{22}$.

Do ponto de vista patogênico é admitido que os transtornos cerebrais sejam secundários a fenômenos trombo-embólicos em vasos do encéfalo. Entretanto, a patogenia da malária nervosa não está completamente esclarecida, apesar das várias pesquisas realizadas nesse sentido. Atualmente dá-se pouco valor à insuficiência de hemoglobina, à falência circulatória generalizada, bem como à anoxia sistêmica, para se emprestar maior importância a mecanismos imunopatológicos, à insuficiência circulatória local e, principalmente, a desordens metabólicas celulares ${ }^{14}, 15$.

Em estudos hematológicos têm sido registradas alterações da coagulação - baixo do fibrinognio $4,8,9$, trombocitopenia, baixa dos fatores V e VIII que possivelmente são tradutoras de coagulação intravascular ${ }^{4}, 8$, determinante de hemorragias encefálicas. O mecanismo pelo qual a malária ocasiona a coagulação intravascular é desconhecido, mas possivelmente ela é devida à hemólise com liberação de substâncias coagulantes, como a fosfatidilserina e a fosfatidiletanolamina ${ }^{4}$.

Maegraith ${ }^{15}$ chama a atenção para o fato de que o quadro clínico e patológico da malária é praticamente o mesmo que o de todas as infecções. A maioria dos fenômenos, incluindo as lesões estruturais no figado e nos rins, é inespecífica. Em infecçōes com Plasmodium berghei, $P$. knowlesi e $P$. falciparum este autor encontrou, no soro do hospedeiro (rato), um fator que inibe "in vitro" a fosforilação oxidativa nas mitocôndrias das células hepáticas de ratos e macacos. Este fator pode ser um dos agentes desen-

* Professor-Assistente, Faculdade de Ciências da Saúde, Universidade d€ Brasilia, Brasil. 
cadeantes das respostas fisiopatológicas do hospedeiro frente à doença. Alguns autores aventam a possibilidade da toxemia secundária à insuficiência hepática ser um fator contribuinte para a determinação do quadro neurológico ${ }^{5}$.

Do ponto de vista anátomo-patológico vale ressaltar que há discrepância entre os achados histo-patológicos e o quadro clínico, pois este parece depender de distúrbios da microcirculação com repercussão sobre a biologia celular, que o microscópio óptico não revela ${ }^{14}$. As lesões do sistema nervoso podem ser divididas em intravasculares, vasculares, perivasculares e extravasculares. As alterações intravasculares são representadas por acúmulo de hemácias parasitadas, parasitas livres, pigmento e diversos componentes celulares do sangue que prejudicam o fluxo sanguíneo, causando estase e oclusão capilar ${ }^{19}$. As lesões perivasculares, observáveis na substância branca, são arredondadas, micronodulares, e tem estrutura histológica variável: hemorrágica, necrótica, ou salientando-se por uma reação neuroglial ou por uma área de desmielinização limitada. As células endoteliais dos pequenos vasos, no centro da lesão, se apresentam vacuolizadas, necróticas, às vezes difíceis de serem vistas, de tal forma que o limite entre o conteúdo do vaso e a proliferação perivascular é pouco nítido. Quanto aos fenômenos extravasculares, observa-se que as hemorragias são em geral perivasculares porém, às vezes intra-adventiciais. $O$ foco de necrose, sempre perivascular, nunca ocorre isoladamente. A reação glial, à custa de microglia, pode acompanhar uma hemorragia ou uma área de necrose, ou, mais frequentemente, uma associação de necrose central com anel hemorrágico, o que foi chamado por Dürck, de granuloma malárico. As lesões neuronais no cortex cerebral, no cortex cerebelar e nos gânglios da base parecem estar relacionadas com a anóxia. Caracterizam-se por retração neuronal, desaparecimento do nucléolo e hiperbasofilia do citoplasma e do núcleo, ou por homogeneização eosinofílica do citoplasma e co núcleo ou, ainda, por desaparecimento de neurônios ${ }^{3}, 13,19$.

O quadro clínico correspondente ao envolvimento do sistema nervoso é constituido por sintomas neurológicos e psiquiátricos. Dos sinais neurológicos, predominam os distúrbios da consciência, desde a sonolência ao coma, e as convulsões que, em geral, são do tipo generalizado, podendo às vezes se manifestar em forma de estado de mal epiléptico $1,7,10,22$. Distúrbios motores de outra natureza podem ocorrer, tais como mioclonias, hemiplegias, monoplegias, acometimentos de nervos cranianos (facial e motores oculares) e ataxia cerebelar $6,7,10,17$. Sinais de irritação meníngea são discretos e manifestações sensitivas difíceis de serem apuradas. Podem ocorrer alteraçōes dos reflexos profundos e pode ser notado o sinal de Babinski, uni ou bilateralmente. Ȧs vezes ocorre síndrome de hipertensão intracraniana ${ }^{20,22}$. Cumpre ressaltar ainda o estado de choque, as alterações respiratórias e a desregulação térmica que, pelo menos em parte, podem ser atribuídas ao acometimento do neuro-eixo.

Do ponto de vista psiquiátrico, vale assinalar os achados de Blocker Jr. e col. ${ }^{3}$ : tentativas de suicídio, ilusōes paranóides e persecutórias, frequentemente relacionadas com a morte de familiares, que se enquadram no que 
fora chamado anteriormente por outros autores de "psicose malárica". Testes psicológicos aplicados em doentes no período de estado da infecção mostram distúrbios da memória recente, da velocidade psicomotora, da integração visuo-motora e da organização visual, sugestivos de disfunção orgânica que regrediram totalmente com a cura do processo infeccioso ${ }^{12}$.

Williams e McFarlane ${ }^{24}$ assinalam que desde que Coggeshall e Kum (1937) demonstraram, pala primeira vez, a presença de anticorpos circulantes após infecção palúdica, vários investigadores, e entre eles McGregor e col. ${ }^{16}$, tem confirmado esta observação. Este autores demonstraram a presença de anticorpos circulantes para o $P$. falciparum, pelo método de dupla difusão do agar gel, usando antígeno malárico extraído de cérebros humanos.

Em casos de malária com acometimento do sistema nervoso o eletrencefalograma é sempre anormal, caracterizando-se por ondas lentas, associadas ou não a sinais irritativos, em geral simétricos, parecendo não haver correspondência entre os achados clínicos e eletrencefalográficos ${ }^{14}$.

$\mathrm{O}$ exame do líquido céfalorraqueano é pouco expressivo e em geral mostra discreta hipertensão, com aumento moderado de células e de proteínas ${ }^{10}$.

Beale e Coni ${ }^{2}$ observaram hipocalcemia em paciente com malária, associada a hiponatremia e hipocaliemia, e julgam que estas alterações possam ser responsáveis pelas miofasciculações que ocorreram nesse caso.

O diagnóstico da malária é confirmado pela descoberta do hematozoário mas, como acentua Guinard ${ }^{10}$ deve ser essencialmente clínico visto que, de acordo com sua experiência, os esquizontes eram raros em $42 \%$ dos casos. Chipman e col. ${ }^{5}$, fazendo referência aos trabalhos de Boshes, Fitz-Hugh e Arbuse, chamam a atenção para o fato de que, em zonas endêmicas, coma e esfregaço positivo para malária não significam que a sintomatologia neurológica seja necessariamente devida à malária, assinalando terem visto três casos nos quais o quadro neurológico era devido a meningite (dois) e a abscesso cerebral (um). Saguet e col. ${ }^{22}$, lembrando as palavras de Bergeret (1948), são de opinião que o diagnóstico pode ser feito mais precocemente mediante punção medular.

Musoke ${ }^{18}$, analisando sua experiência em 20 casos em crianças, conclui que o diagnóstico é firmado se: o paciente tiver febre alta, distúrbio da consciência e/ou convulsões e não for imune à malária; houver esfregaço positivo para $P$. falciparum; não houver outra condição mórbida que justifique os sintomas; houver resposta boa e rápida à medicação específica.

Classicamente a malária tem uma evolução rápida, fatal ou benigna, e, do ponto de vista neurológico, raramente deixa sequelas. Entretanto, Sanohko e col. ${ }^{23}$ fazem referência a 7 casos cuja evolução foi particular, não somente pela duração dos transtornos de consciência, mas sobretudo pela intensidade e duração dos distúrbios neurológicos, após a recuperação da consciência. Saguet e col. ${ }^{22}$ consideram importantes para a avaliação do prognóstico, sendo sinais e sintomas desfavoráveis: coma profundo ou prolongado; estado de choque; estado de mal epiléptico; distúrbios térmicos 
persistentes e intensos; estado de desnutrição grave; sinais digestivos graves e anemia com número de hemácias inferior a $2.000 .000 / \mathrm{mm}^{3}$.

\section{O B S E R V A C O E S}

CASo 1 - O.S., 48 anos, sexo masculino, branco, solteiro, natural da Bahia (Registro UISS 48602), deu entrada no Pronto Socorro obnubilado, informando mal, referindo apenas febre e anorexia, e dizendo-se procedente de zona endêmica da malária. Ao exame clínico observou-se mau estado geral, torpor, mucosas descoradas, levemente ictéricas. Pulso 100 batimentos por minuto. Pressão arterial $85 \times 65$ $\mathrm{mmHg}$; tempertura $35,8^{\circ} \mathrm{C}$. Estertores disseminados em ambos os pulmões. Sopro sistólico pancardíaco. Hepatomegalia dolorosa a $10 \mathrm{~cm}$ da reborda costal. Esplenomegalia moderada. Mioclonias. Discutivel rigidez de nuca. Hiperreflexia profunda generalizada. Reflexos plantares inaparentes. Fundoscopia normal. Pupilas iguals reagindo à luz. Nistagmo vertical espontâneo. Durante o exame o paciente apresentou uma crise convulsiva tônico-clônica generalizada. Exames laboratoriais - Pesquisa de hematozoário positiva ( $P$. falciparum); Hemoglobina 9,17 g\%; Hematócrito $27 \%$; Leucograma: Leucócitos $7.100 / \mathrm{mm}^{3}$ (bastonetes $5 \%$, segmentados $83 \%$, linfcitos $6 \%$, monócitos $6 \%$ ). Bilirrubinas: total $0,6 \mathrm{mg} \%$; direta $0,5 \mathrm{mg} \%$; indireta $0,1 \mathrm{mg} \%$. Transaminases abaixo de 15 unidades. Fosfatase alcalina 8,2 unidades Bodanski. Sódio $138 \mathrm{mEq} / \mathrm{l}$. Potássio $6 \mathrm{mEq} / \mathrm{l}$. Cálcio $4,5 \mathrm{mEq} / \mathrm{l}$. Cloro 100 $\mathrm{mEq} / \mathrm{l}$. pH 7,39. Uréia $210 \mathrm{mg} \%$. Creatinina $9,9 \mathrm{mg} \%$. Electrocardtograma normal. Radiografias de torax: pulmões normais, hepatoesplenomegalia e calcificaçōes musculares com aspecto de cisticerco. Exame de urina: proteínas $(+++)$, leucócitos (8-9/campo), hemácias (7-8/campo), cilindros hialinos $(+)$, cilindros granulosos $(+)$.

Tendo sido diagnosticado coma malárico e insuficiéncia renal aguda o paciente foi medicado com cloroquina, pirimetamina e sulfadoxina, além dos cuidados para a insuficiência renal e para controlar as convulsões, tendo alta trinta dias depois, melhorado.

CASo 2 - A.F.S., 18 anos, sexo masculino, pardo ,solteiro, lavrador, natural de Mato Grosso (Registro UISS 64072). Deu entrada no Pronto Socorro em estado de torpor, não respondendo às perguntas. O acompanhante informava que havia 20 dias o paciente vinha sofrendo de febre e anorexia, além de diarréia com 3-4 evacuações diárias de fezes esverdeadas, escuras. Ao exame clínico apresentava-se intensamente anêmico, anictérico, torporoso, não atendendo às solicitações, olhando como que atônito em torno de si, confuso. Movimentava-se de modo desordenado, com gestos largos e atáxicos. Pulso 76 batimentos por minuto. Pressão arterial $100 \times 65 \mathrm{mmHg}$. Temperatura $39^{\circ} \mathrm{C}$. Apresentava sopro sistólico pancardíaco. A palpação do abdome e a escuta pulmonar estavam normais. Exames laboratoriais - Pesquisa de hematozoário positiva $(P$. falciparum). Hematócrito $22 \%$. Uréia 24 $\mathrm{mg} \%$. Creatinina $1 \mathrm{mg} \%$. Glicose $115 \mathrm{mg} \%$. Proteinas totais no sangue $6,1 \mathrm{mg} \%$, sendo $3,6 \mathrm{~g} \%$ de albumina e $2,5 \mathrm{~g} \%$ de globulinas. Tempo de protrombina 13" (80\%). VDRL negativo. Reação de Machado-Guerreiro positiva. Exame de urina: hemácias raras, leucócitos (8/campo), cilindros granulosos finos $(+++)$, bactérias $(++)$. Medicado com cloroquina, sulfato ferroso, vitamina $K$, o paciente teve alta em regulares condiçōes.

CASo 3 - J.A.S., 40 anos, sexo masculino, pardo, solteiro, lavrador, natural do Rio Grande do Norte (Registro UISS 56977), deu entrada no Pronto Socorro contando que havia dois meses sofrera episódios de febre alta com calafrios, sendo diagnosticada maleita. Desde então notou fraqueza generalizada, com dificuldade para caminhar, tendo sofrido algumas quedas. Piorou progressivamente até surgir dificuldade de articulação da palavra e na realização de outros movimentos que se tornaram inseguros. Tomou cloroquina no início da doença. Ao exame clínico observou-se: Pulso 70 batimentos por minuto. Pressão arterial $120 \times 80 \mathrm{mmHg}$. 
Temperatura $37,5^{\circ} \mathrm{C}$. Hepatoesplenomegalia. Sinal de Romberg presente. Marcha atáxica. Força conservada. Ataxia do tipo cordonal posterior nos quatro membros. Hipotonia nos membros inferiores. Reflexos aquileus abolidos e patelares diminuidos. Nos membros superlores apenas os tricipitais estavam presentes. Cometia erros na avaliação da posição dos dedos dos pés no espaço. Exames laboratoriais - Pesquisa de hematozoário positiva $(P$. falciparum). Hematócrito $36 \%$. Hemoglobina $11,9 \%$. Leucograma: leucócitos $5.000 / \mathrm{mm}^{3}$ (segmentados $40 \%$, linfócitos 36\%, monócitos 10\%, eosinófilos 12\%, basófilos 2\%). Tempo de protrombina 100\%. Proteínas totais $8,9 \mathrm{~g} \%$, sendo $6 \%$ de albumina e $2,4 \mathrm{~g} \%$ de globulinas. Uréia $40 \mathrm{mg} \%$. Creatinina $1,4 \mathrm{mg} \%$. Glicose $100 \mathrm{mg} \%$. VDRL negativo. Reacão de MachadoGuerreiro não reagente. Exame de urina sem anormalidades. Exame de fezes: $A$ duodenale. Liquido cefalorraqueano contendo 5 células $/ \mathrm{mm}^{3}$, glicose $80 \mathrm{mg} \%$, proteínas $10 \mathrm{mg} \%$, cloretos $730 \mathrm{mg} \%$, VDRL negativo. Medicado com antitérmicos, cloroquina, primaquina e tetracloroetileno, o paciente teve alta em boas condições.

Caso 4 - J.T.G., 65 anos, sexo masculino, pardo, casado, natural de Goiás (Registro UISS 66766), deu entrada no Pronto Socorro contando que estivera 7 dias antes trabalhando em zona endêmica de malária, passando a sofrer em seguida de cefaléia intensa, calafrios e tremores. Gradativamente tornou-se torporoso e, na data da internação, não reconhecia as pessoas. Ao exame clínico apresentavase comatoso, reagindo mal aos estímulos dolorosos. Ictérico. Taquipnéico. Pupilas em miose. Pulso 140 batimentos por minuto. Pressão arterial $100 \times 60 \mathrm{mmHg}$. Temperatura $37^{\circ} \mathrm{C}$. Hipofonese das bulhas cardiacas e dor à palpacão do hipocôndrio direito. Exames laboratoriais - Pesquisa de hematozoário positiva ( $P$. falciparum). $O$ paciente faleceu em choque algumas horas depois.

Laudo anátomo-patológico (A-71-101) * - O exame histológico em vários níveis do sistema nervoso mostra acentuada congestão de vasos superficiais e profundos, com proeminência dos vasos corticais e medulares, por hemácias parasitadas e pigmento malárico. Os espaços subaracnóideos e de Virchow mostram alargamento. A substância cinzenta cerebral e cerebelar mostra discretas áreas focais de hemorragia com hemácias parasitadas ou somente o pigmento malárico. Ao nivel da substância branca são vistas numerosas áreas focais de hemorragias anulares e cilindricas, algumas com vasos centrais necrosados. São vistas numerosas áreas subcorticais de desmielinização e áreas ocupadas por pigmento malárico livere, inclusive na camada molecular do cerebelo. As veias subependimárias são dilatadas e congestas. Diagnóstico: Malária cerebral, na forma aguda.

CASo 5 - A.R.S., 39 anos, sexo feminino, branca, casada, doméstica, natural da Bahia (Registro UISS 69521), deu entrada no Pronto Socorro com queixa de queda do estado geral, referindo, havia cerca de 8 dias, dor abdominal difusa, sangramento vaginal, febre, anorexia e diarréia, que a obrigaram a guardar o leito. Ao exame clinico observou-se uma paciente torporosa, respondendo mal às solicitações. Ictérica. Temperatura de $35,8^{\circ} \mathrm{C}$. Pressão arterial $80 \times 60 \mathrm{mmHg}$. Pulso 100 batimentos por minuto. A palpação abdominal revelou um abdome tenso, bastante doloroso. Foi vista pelo ginecologista que diagnosticou anexite. Ao exame neurológico observamos apenas, além do distúrbio da consciência, rigidez de nuca. Exames laboratoriais - Pesquisa de hematozoário positiva ( $P$. falciparum). Hematócrito 30\%. Hemoglobina $7,8 \mathrm{~g} \%$. Leucograma: leucócitos $5.100 / \mathrm{mm}^{3}$ (bastonetes $12 \%$, segmentados $38 \%$, linfócitos $40 \%$, monócitos $10 \%$ ). Uréia $101 \mathrm{mg} \%$. Creatinina $3,4 \mathrm{mg} \%$. Glicose $80 \mathrm{mg} \%$. Sódio $135 \mathrm{mEq} / \mathrm{l}$. Potássio $7,9 \mathrm{mEq} / \mathrm{l}$. Cálcio $3,5 \mathrm{mEq} / \mathrm{l}$. Não foi feito exame do líquido cefalorraqueano, devido ao estado precário da paciente. Medicada com transfusões de sangue, diuréticos osmóticos e cloroquina a paciente, no segundo dia, apresentou hiperpotassemia, provavelmente relacionada a irsuficiência renal. No dia seguinte faleceu em choque.

* Agradecemos ao Dr. Hans Japp os exames anátomo-patológicos feitos nos casos 4,5 e 6. 
Laudo análomo-patológico (A-72-04) - O exame histológico em vários niveis do tecido nervoso mostra congestão de vasos superficiais e profundos, por hemácias parasitadas e pigmento malárico, com discreta proliferaçāo de células mononucleares no espaço subaracnóideo. Ao nivel das substâncias cinzenta e branca são vistos trombos hialinos e numerosos vasos com colônias bacterianas intraluminais. Difusas áreas de destruiçāo do revestimento ependimário, mostram corpos amiláceos no tecido subjacente. Diagnóstico: Malária cerebral, forma embólico-parasitária. Embolia bacteriana.

Caso 6 - V.N., 35 anos, sexo masculino, branco, solteiro, natural de Goiás (Registro UISS 76010), foi trazido ao Pronto Socorro por apresentar icterícia e febre. Ao exame físico observou-sa paciente torporoso, asteniado, ictérico. Ausculta pulmonar e cardíaca sem alterações. Abdome moderadamente tenso, doloroso à palpação dos hipocêndrios. Hepatoesplenomegalia. Pressão arterial $103 \times 60 \mathrm{mmHg}$. Pulso 88 batimentos por minuto. Temperatura $36,3^{\circ} \mathrm{C}$. Exames laboratoriais Pesquisa de hematozoário positiva $(P$. falciparum). Hematócrito 20\%. Hemoglobina $7,5 \mathrm{~g} \%$. Leucograma: leucócitos $13.400 / \mathrm{mm}^{3}$ (bastonetes $22 \%$, segmentados $32 \%$, linfócitos $43 \%$, monócitos $3 \%$ ). Creatinina 2,7\%. Sódio $145 \mathrm{mEq} / 1$. Potássio $5,4 \mathrm{mEq} / \mathrm{l}$. $\mathrm{pH}$ 7,21. $\mathrm{pCO}_{2} 20 \mathrm{mmHg} . \mathrm{HCO}_{3} \quad 7,5 \mathrm{mEq} / \mathrm{l}$. Coagulograma: lator $\mathrm{V}$ $90 \%$ (22'). Fibrinogênio $76 \mathrm{mg} \%$. Tempo de protrombina 14\%. Tempo de coagulaçāo 13'55". Diagnóstico: Coagulação intravascular aguda. O pacienie, medicado para correção tẹ acidose metabólica e coagulação iniravascular, não melhorou, passando a apresentar hemorragia digestiva, vindo a falecer dois dias depois.

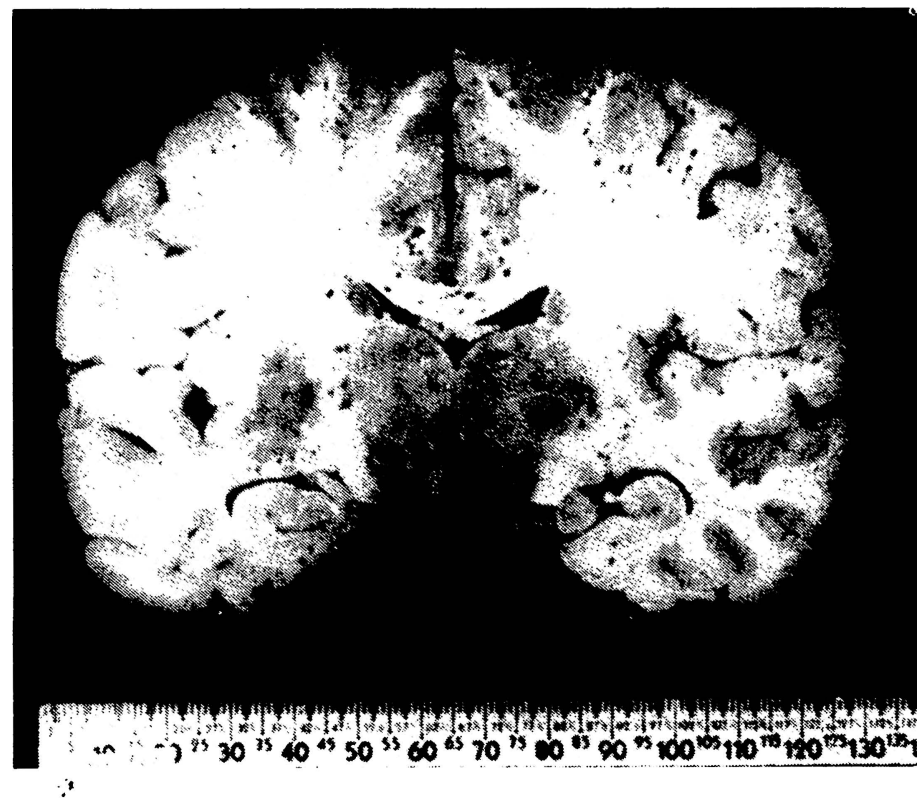

Fig. 1 - Caso 6. Abundantes e difusas áreas hemorrágicas puntiformes corticais.

Laudo anátomo-patológico (A-72-40) - o exame histológico em vários niveis do tecido nervoso cerebral e cerebelar mostra espaço subaracnóideo alargado. Proliferação celular mononuclear e vasos leptomeníngeos congestos com lumen ocupado por hemácias parasitadas e com pigmento malárico em situação marginal. 


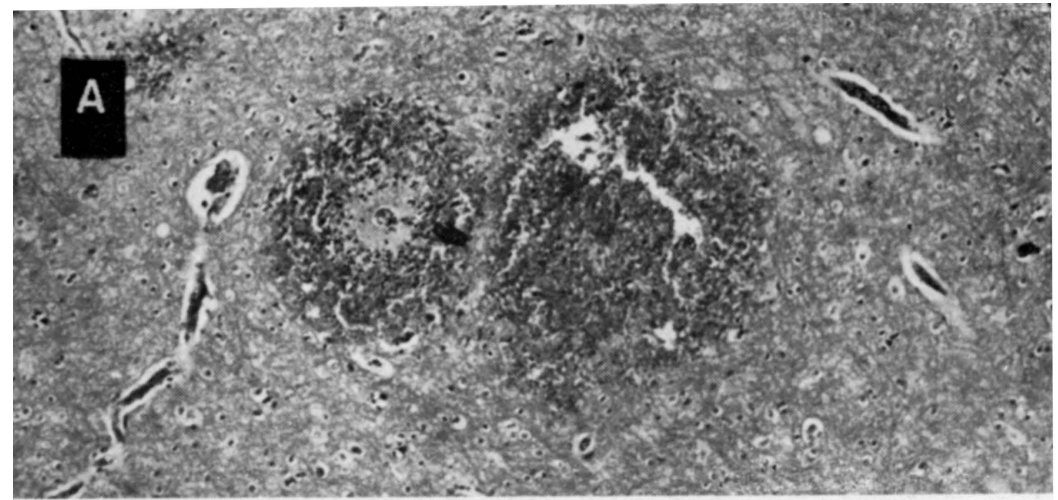

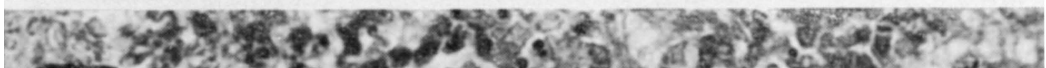

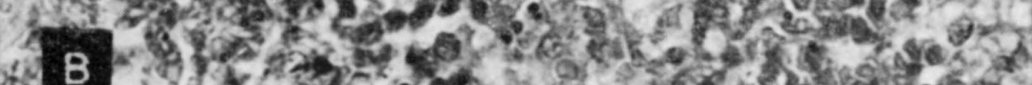
in -

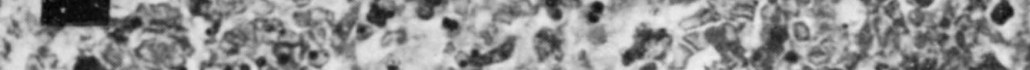

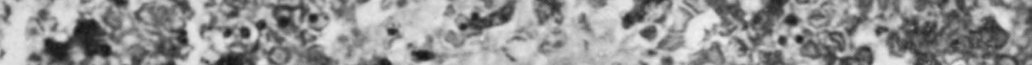

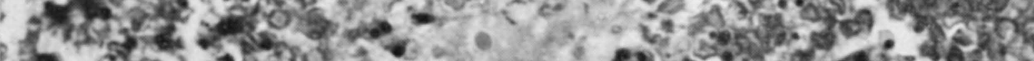

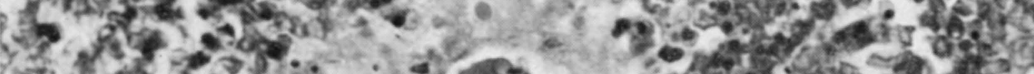

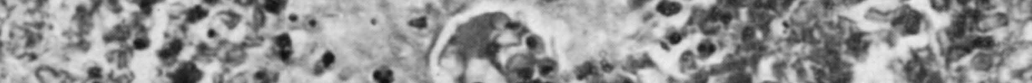

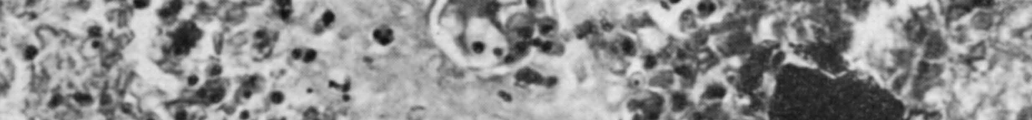

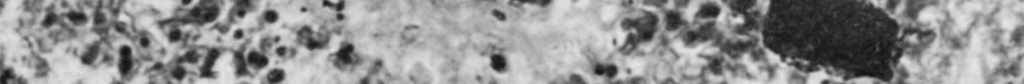
$b^{3}$ a

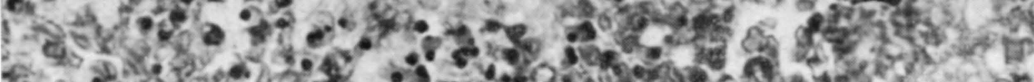

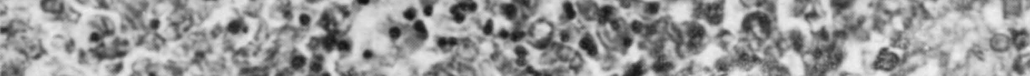

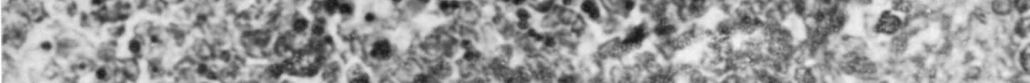

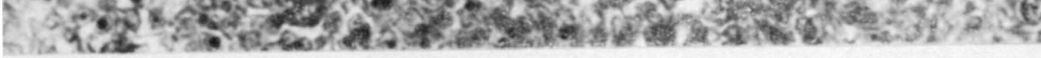

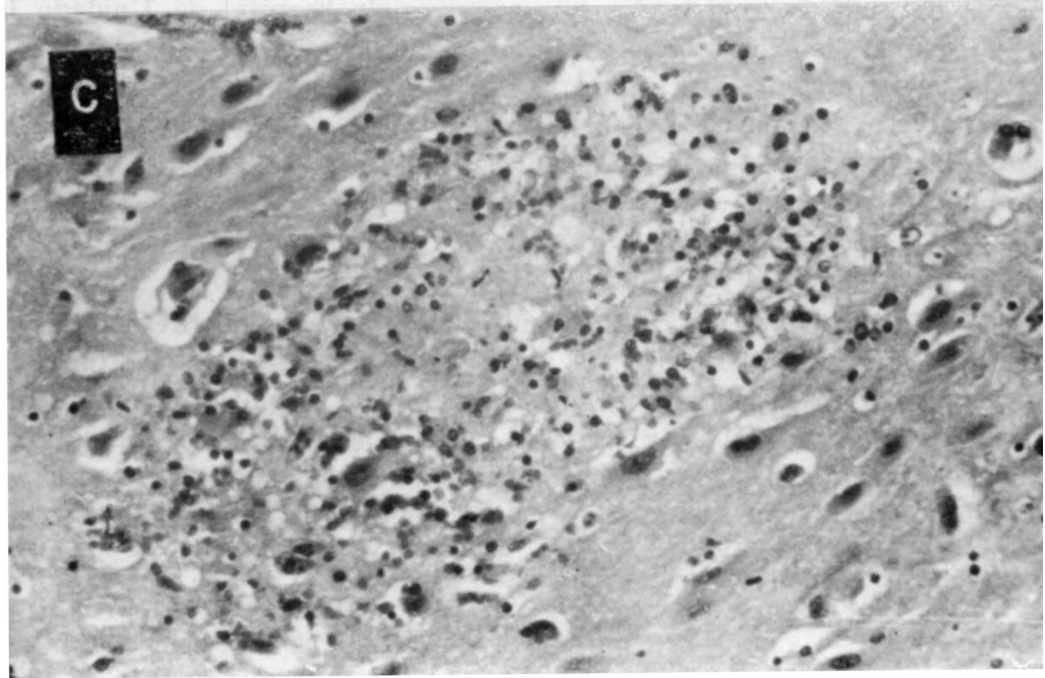

Fig. 2-Caso 6. Em A, hemorragia anular na substância branca (H.E. $25 \times$ ); em $B$, mesmo aspecto que em A, em maior aumento ( $H . E$. $160 \times)$; em $C$, "granuloma" em fase inicial, com proliferação glial em torno de foco necrótico (H.E. $160 \times$ ). 
Ao nivel da substancia cinzenta, bem como na substância branca subcortical, observa-se intensa proeminência vascular, com obliteração capilar, áreas multifocais. de hemorragia cilindrica e anular, perivascular, e pigmentação malárica livre. Algumas áreas mostram necrose vascular e nitida proliferação microglial, com esboço de formação nodular malárica de Dürck. Finalmente observa-se áreas esparsas de desmielinizaçāo subcortical e sofrimento neuronal difuso e não seletivo. Diagnóstico: Malária cerebral, forma aguda (Figuras 1 e 2).

\section{O M E N T A R I O S}

Nossa pequena casuística vem confirmar o que se encontra na literatura médica a respeito do tema. Vale observar, entretanto, que deve-se reservar a denominação de malária nervosa àquelas formas de malária que atinjam seletivamente o neuro-eixo, determinando manifestações neurológicas não acompanhadas de sintomatologia sistêmica, ou àqueles casos que deixaram sequelas, como testemunho da maior agressão ao sistema nervoso central (Sanohko e col. ${ }^{23}$ ).

O caso 3 representa, a nosso ver, exemplo de forma extremamente rara de malária medular com sintomatologia cordonal posterior. Os demais são apenas casos graves de malária sistêmica nos quais o sistema nervoso, como os outros sistemas da economia, foi envolvido. Nesses casos torna-se difícil afirmar se o óbito que porventura ocorra é devido ao acometimento do sistema nervoso central, sendo às vezes bem nítida a falência renal (casos 1 e 5) ou o distúrbio hematológico grave, do tipo coagulação intravascular (caso 6), que não se limita à vasculatura cerebral. Além disso, como no caso 5 , a associação de outras infecções bacterianas pode contribuir para o êxito letal.

Nesse nosso levantamento foram compulsados 101 casos de pacientes sofredores de malária, registrados nos arquivos do hospital da Unidade Integrada de Saúde de Sobradinho (Sobradinho, DF), o que nos revela uma incidência relativamente alta de cerca de $6 \%$, de formas com agressão ao sistema nervoso, todas causadas pelo Plasmodium falciparum. Esta alta incidência, se comparada com os achados de Daroff em soldados americanos no Vietnã ${ }^{7}$, talvez deva ser atribuída ao mau estado de saúde das populaçōes do interior do Brasil, que as torna menos resistentes às infecções em geral.

Os achados clínicos nos mostraram que, além dos distúrbios de consciência, as convulsões e os sinais meníngeos são os mais encontradiços. Vale assinalar o fato de termos observado formas álgidas, não enfatizadas na literatura, que talvez sejam devidas ao acometimento do centro termoregulador diencefálico. Nos casos estudados os achados laboratoriais e anátomo-patológicos não nos sugeriram qualquer nova observação a respeito da fisiopatologia da malária.

R E S U M O

Depois de revisão da literatura sobre manifestações neurológicas da malária, são relatados 6 casos de pacientes que estiveram em tratamento na 
Unidade Integrada de Saúde de Sobradinho (Brasília, DF), e que apresentavam formas graves de malária com envolvimento do sistema nervoso central. Um dos casos mostrava acometimento predominante da medula, com sindrome cordonal posterior. Três pacientes faleceram e o exame histopatológico do sistema nervoso revelou lesões típicas da malária, confirmando o diagnóstico.

\section{S U M M A R Y}

\section{Neurological manifestations of malaria}

After a comprehensive review of the literature on neurological manifestations of malaria six cases observed in the Unidade Integrada de Saúde de Sobradinho (Brasília - DF) are reported. All patients but one presented very severe forms of malaria with neurological symptoms. One patient showed signs of involvment of the spinal cord with cordonal posterior syndrome. Three patients died and the histopathological examination confirmed the diagnosis.

\section{R E F E R N C I A S}

1. AUSTREGESILO, A. - Des troubles nerveux dans quelques maladies tropicales. Rev. Neurol. (Paris) T. 1:1-21, 1927.

2. BEALE, P. J. \& CONI, N. K. - Cerebral malaria. Ann. trop. Med. Parasit. $64: 243,1970$.

3. BLOCKER Jr., W. W.; KASTL, A. J. \& DAROFF, R. B. - The psychiatric manifestations of cerebral malaria. Amer. J. Psychiat. 125:192, 1968.

4. BOROCHOVITZ, D.; CORSLEY, A. L. \& METZ, J. - Disseminated intravascular coagulation with fatal haemorrage in cerebral malaria. Brit. Med. J. 2:710, 1970.

5. ChIPMAN, M.; CADIGAN Jr., F. C. \& BENJAPONGSE, W. - Involvment of the nervous system in malaria in Thailand. Trop. Geogr. Med. 19:8, 1967.

6. COLlOMB, H.; REY, M.; DUMAS, M.; NOUhOUAyi, A. \& PETIT, M. - Les hemiplegies au cours du paludisme aigu. Bull. Soc. Med. Afr. Noire Lgue. Pr. 12:791, 19 ỏ7.

7. DAROFF, R. B.; DELleR Jr., J. J.; KASTL, A. J. \& BLOCKER Jr. W. Cerebral malaria JAMA 22:679, 1967.

8. DENNIS, L. H.; EICHELBERGER, J. W.; INMAN, M. B. \& CONRAD, M. E. Depletion of coagulation factors in drug-resistant $P$. falciparum malaria. Blood 29:713, 1967.

9. DEVAKUL, K.; HARINASUTA, T. \& REID, H. A. - ${ }^{225}$ I labelled fibrinogén in cerebral malaria. Lancet 2:886, 1966.

10. GUINARD, J. - Le paludisme pernicieux du nourrisson et de l'enfant. Ann. Pediat. 58:646, 1965.

11. HILL, G. J.; KNIGHT, V.; COATNEY, G. R. \& LAWLESS, D. K. - Vivax malaria complicated by aphasia and hemiparesis. Arch. Int. Med. 112:863, 1963.

12. KASTL, A. J. - Psychological testing of cerebral malaria patients. J. Nerv. Ment. Dis. 147:553, 1968.

13. LEMERCIER, G.; REY, M. \& COLLOMB, H. - Lesions cerebrales dans le paludisme de l'enfant. Bull. Soc. Path. exotique 59:533, 1966.

14. LEMERCIER, G.; BERT, J. \& NOUHOUAYI, A. - Le neuropaludisme: aspects eletroencephalographiques et neuropathologiques. Path. Biol. 17:459, 1969. 
15. MAEGRAITH, G. - Oxidative phosphorilation in malaria. Ann. Soc. belge Med. trop. 45:275, 1965.

16. MC GREGOR, I. A.; HALL, P. J.; WILliaMS, K. \& HARDY, C. L. S. Demonstration of circulating antibodies to $P$. falciparum. Nature 210:1384, 1966.

17. MOREIRA DA FONSECA, J. - Formas Nervosas do Impaludismo. Editora Flores e Manos, Rio de Janeiro, 1935.

18. MUSOKE, L. K. - Neurological manifestations of malaria in children. East African med. J. 43:561, 1966.

19. RAVENS, J. R. - Histopathological changes in the central nervous system in acute malaria. J. Neuropathol. Exper. Neurol, 26:176, 1967.

20. REILLY, D, J. - Intracranial hypertension in malaria. New Engl. J. Med. $281: 46,1969$.

21. ROTHE, H. - Hundred cases of cerebral malaria. E. Afr. Med. J. 33:405, 1956.

22. SAGUET, H.; MORINEAUD, J.-P.; REVIL, H.; THOMAS, J. \& MAFART, Y. - Quelques reflexions a propos de 45 cas de comas palustres confirmés parasitologiquement chez des enfants de moins de six ans. Med. trop. 27:606, 1967.

23. SANOHKO, A.; DAREYS, J. P. \& CHARREAU, M. - Etat encephalitique prolongé et accés pernicieux palustres. Bull. Soc. Med. Afr. Noire Lgue. fr. 13:662, 1968 .

24. WILliAMS, A I. O. \& MCFARLANE, H. - Malarial antigen from human brain. Clin. exp. Imunol. 3:953, 1968.

Departamento de Medicina Especializada - Faculdade de Ciências da Saúde - Universidade de Brasilia - Brasilia, DF - Brasil. 